\title{
Editorial: Asia-Pacific Science Education (APSE): Expanding Research on Equity and Inclusion Science Education in the Asia-Pacific Region
}

\author{
Sonya N. Martin \\ Editor-in-Chief \\ Department of Earth Science Education, Seoul National University \\ o8826, Seoul, Republic of Korea \\ sonya_martin@fastmail.com
}

Received: 10 December 2020 | Accepted: 10 December 2020

In January 2021, the Korean Association for Science Education (KASE) will hold their annual international winter conference (see https://www.kase2O21 .org/). The theme for the conference is "Walking Together Toward Inclusive Science Education by Creating Equitable Science Learning Opportunities" (공평한 과학 학습 기회를 통해 함께 하는 과학 교육 만들기). Inclusive science education refers to the practice of "including" students with diverse learning needs, such as students with special education needs and culturally and linguistically diverse students, in classrooms with regular education students. Ideally, these students would receive appropriate educational support designed to maximize their strengths while engaging them in learning content similar to their peers during the same science lesson. In education systems with sufficient resources and well-trained teachers, these students can benefit from being educated alongside their peers. In the Asia-Pacific region, research specifically focusing on the needs of diverse students is emerging. To support researchers to learn more about this topic and to encourage more interest in pursuing research agendas exploring equity-related topics, the KASE organization invited 11 international scholars and their collaborators to share their research focused on equity issues in science teaching and learning.

Eight of these scholars have contributed manuscripts for a special issue of APSE focusing on the same topic. As such, this issue features papers exploring equity issues related to special education, cultural and linguistic minorities, and teaching and learning in informal science education contexts around the world - but with connections and implications for research and teaching in 
the Asia-Pacific region. It is our hope that these papers will inspire our readers to begin expanding and developing a more comprehensive research agenda focused on equity and inclusion science education in the Asia-Pacific region. In the sections that follow, I am pleased to introduce the papers appearing in Issue 6.2 and I invite all of our APSE readers to take full advantage of our openaccess papers.

Overview of Special Issue Papers

In the first paper in the issue, Okhee Lee describes a yearlong fifth-grade science curriculum from the United States to illustrate how US-based policy documents, including $A$ Framework for $K-12$ Science Education (National Research Council, 2012) and Next Generation Science Standards, have shaped science and language instructional shifts in science classrooms. Her analysis argues that these shifts are mutually supportive of each other and can be effective for promoting rigorous science learning and rich language development for secondlanguage learners. As the countries in the Asia-Pacific region see increased growth in immigration, resulting in shifts in demographics of school-age children, this work has the potential to support researchers in the region to more closely examine local educational policies that have an impact on both science and language instruction.

In their discussion of systemic injustices in informal science learning contexts, Angela Calabrese-Barton, Won Jung Kim, and Edna Tan demonstrate how a participatory research design using a "justice-oriented framework of rightful presence" can support educators and youth to collaboratively identify and transform narratives and practices that position youth on the periphery in informal learning environments. Drawing from their lived experiences working at a STEM camp for adolescent youth, the authors discuss "insights, dilemmas, and implications regarding justice-oriented pedagogies and their possibilities for rightful presence in science education" that are applicable in contexts around the world. Shannon Mary Daniel and Minjung Ryu share findings from a community-based afterschool STEM enrichment program designed to engage resettled Chin refugee teens to develop their English language proficiency while learning about weather, climate, and climate change with a focus on developing these students' critical st EM literacy practices. The authors share examples from the program to illustrate four design principles used to support critical sтем literacy and English learning and discuss implications for science educators who work with displaced or resettled youth in the Asia-Pacific regions. Christina Siry introduces APSE readers to research on 
plurilingual students' interactions in science drawn from several studies from her research group focusing on the multilingual context of Luxembourg. Using findings from case studies, she encourages researchers to situate difference as a resource for teaching and learning by presenting dialogic pedagogies and multimodal methodologies as necessary tools for expanding equitable practices in science education when working in culturally and linguistically diverse contexts. This paper offers both methodological and theoretical insights for researchers grappling with how to support science teaching and learning in classrooms that are becoming increasingly diverse with regard to race, ethnicity, culture, and language.

The next set of papers focus on addressing issues related to special education. Authored by Susannah Boyle, Karen Rizzo, and Jonte Charez Taylor, the first paper provides readers with resources and suggestions for incorporating Universal Design for Learning, multimodal representation, the arts, and communicative technologies in the teaching of science to help reduce unnecessary language barriers that can prevent students with special education needs from participating in and learning school science. As research exploring special education and science in the Asia-Pacific is emerging as a new field of interest, this paper offers APSE readers a useful introduction to many related topics. Tang Wee Teo offers a paper exploring Singapore primary science teachers' views and practices about including students with special needs in regular science classrooms. Using Rasch analysis to explore teacher self-efficacy views in teaching science to students with special education needs and for teaching science in inclusive classrooms, this study shows that while teachers have positive views about students, they feel inadequate in their support of these learners and are in need of more school support to be able to effectively provide the accommodations and modifications students need. This study, which offers APSE readers new insights about special education and science teaching in the Asia-Pacific region, raises important questions about the need for more research focused on inclusive science teaching, both in the region and globally.

Informal learning environments offer another important area for research focused on equity issues. In this issue, Tali Tal uses Gutiérrez and Rogoff's (2003) repertoires of practice to conduct a document analysis and interviews with local stakeholders in an effort to understand whether differences in learning between Jewish and Arab students in Israel is only a matter of students' access to resources and opportunities or whether cultural differences and cultural change toward integrating learning opportunities in out-of-school environments may also play an important role. This paper has important implications for research on informal learning environments shared by people whose different educational and social practices differently inform their views about how 
to use out-of-school time and resources. Jennifer Adams draws from a liberatory science learning framework to describe a collaborative research project aimed at unpacking the relationship between teacher identity and learning to teach. Following a description of the relationship between teacher reform initiatives and science-rich informal science learning environments, a theoretical framework connecting teacher learning, teacher identity, and informal science learning environments is introduced and discussed in relation to research and practical implications about how to use this theory to advance understanding about teacher identity and learning in informal education settings.

In addition to the papers contributed by our invited KASE conference speakers, this issue also includes a series of papers contributed by KASE member researchers exploring science education issues in Korea and the Asia-Pacific region. Nam-Hwa Kang, Hunsik Kang, Seungho Maeng, Jongwon Park, and Eunyoung Jeong present findings from a study describing the development of a self-assessment instrument for in-service teachers designed to allow teachers to assess their teaching competency focusing on teaching for core competence in science. Building from teachers' perceptions of their own science teaching competency, the authors draw implications for designing PD programs for competency-based teaching - especially in the context of Korean science teaching. Eun-jeong Yu and Chan-Jong Kim share a unique qualitative study to examine identity formation of pre-service science teachers who have transitioned from science to science education majors. Their analysis revealed that identity formation was informed by life history, which is charted using in-depth narrative interviews, story timelines, and participant drawings. The study has implications for science teacher education programs in Korean education contexts and beyond. Jueun Jung, Jina Chang, and Jisun Park share research examining Korean elementary school students' reasoning and development of learning progressions related to changes in state of water. This study offers important insights into students' knowledge and understanding of water phase changes that are widely applicable and discusses how science curriculums can be structured to reflect these progressions in reasoning from Grades $3-5$ to reflect students' conceptual development. The paper ends with discussion about how to provide appropriate science instruction to support students' long-term progression of reasoning. Gahyoung Kim, Kongju Mun, and Hyunju Lee share findings from their use of issue concept (IC) maps with middle school students to document and track changes in students' ideas 
about socio-scientific issues (SSI), such as fine dust. Their study describes how IC maps developed by students learning about fine dust were not only useful for representing students' ideas, but also to show how students' ideas changed as their awareness about the causes and effects of fine dust grew as a result of the activities in which they participated in this ssi program. This study both introduces IC maps as an instructional tool for exploring complicated ssi related issues and expands our understanding of how adolescents think about and understand fine dust, which is a huge health concern in Korea and the region. Seungho Maeng investigated a learning progression of middle school students' understanding of geoscience content and geocognition using a GeoMapApp-based assessment. Using Rasch analysis, students' geocognition learning progressions were described and presented at various levels to identify progress variables integrating geoscientific reasoning practices with geoscience content. Understanding students' geocognition learning progressions is helpful for science teachers in general, but as the Asia-Pacific region is particularly affected by changes in plate tectonics, their improved understanding can especially benefit students to better understand the local environment. The final paper in this issue comes from colleagues in Singapore and Australia, Chee Leong Wong, Kueh Chin Yap, and Hye-Eun Chu, who describe a framework for defining scientific concepts in which teachers, rather than relying on rote memorization, are encouraged to draw students' attention to common features of scientific definitions that can help students to analyze and redefine scientific concepts in ways that can promote improved understanding as a strategy for learning scientific concepts. The authors suggest this pedagogical strategy may be particularly useful for introducing students to a systemic method for learning about concepts that differ from teaching strategies that promote memorization.

Invitation to Contribute to a Special Issue on STEAM Education in the Asia-Pacific Region

The integration of the arts in the teaching of STEM subjects (STEAM) is an innovative approach to teaching science that has been tried out or adopted in several countries in and outside the Asia-Pacific region. The term "arts" covers a broad area including visual arts (drawing, photography, etc.), the humanities (history, literature, etc.), and social-cultural practices or products (media façade, traditional house architecture, musical instruments, etc.). Currently there are many publications on STEAM education in Korea, where STEAM has been implemented in the national curriculum since 2012. Most of these 
publications are in Korean, with a few papers appearing in English, and there have been few publications from other Asia-Pacific countries relating to the integration of non-science subjects in the teaching of science. In some of these countries, STEAM is just beginning to be considered as a possible pedagogical approach in the revision of national school curriculums, so there is still much to be learned from scholars in the field about this topic.

APSE Co-Editor, Hye-Eun Chu, is serving as the guest editor for this upcoming special issue on the development and implementation of STEAM curriculums for students in or from the Asia-Pacific region. Contributions can be submitted through the APSE Editorial Manager system and will be reviewed and considered for publication in the June 2021 issue (7.1). Of particular interest are reports, position papers, and studies describing the impact of STEAM on student learning and student perception of science and science study. In addition, evaluations of programs using a STEAM approach are also encouraged to be submitted. This special issue is anticipated to make a significant contribution to research in innovative approaches to science teaching/learning by investigating the pedagogical potential of integrating STEAM in the science classroom. Please visit the APSE website to download the Call for Papers for more information.

\section{$4 \quad$ Looking Forward to the Future}

While this year has brought many challenges that science educators, researchers, and teachers will be grappling with for years to come, for APSE, 2020 has also been a time for new beginnings, as we have published our first two issues with Brill | Sense. As articles published in issue 6(1) have now been accessed nearly 2,00o times in just 6 months, it seems our transition from Springer to Brill | Sense has been a success. We expect the APSE journal will continue to grow and develop in the next year as we continue to expand our readership and strengthen our connections with science education researchers and teachers in the Asia-Pacific region and beyond.

\section{About the author}

Sonya N. Martin is a Professor in the Department of Earth Science Education at Seoul National University in Seoul, Republic of Korea. Sonya holds a bachelor's degree in biology from Bryn Mawr College, and master's degrees in elementary education and in chemistry education from the University of Pennsylvania in 
the United States. She also holds a doctoral degree in science education from Curtin University in Australia. Her research focuses on identifying science teacher practices that promote learning for diverse students and on promoting the professionalization of science teachers through classroom-based participatory research. She is the Editor-in-Chief of Asia-Pacific Science Education and serves as an editorial board member for Research in Science Education and Cultural Studies of Science Education.

\section{References}

Gutiérrez, K.D., \& Rogoff, B. (2003). Cultural Ways of Learning: Individual Traits of Repertoires of Practice. Educational Research, 32(5), 19-25.

National Research Council (2012). A Framework for K-12 Science Education: Practices, crosscutting concepts, and core ideas. National Academies Press. 